\title{
STUDY OF SERUM URIC ACID IN CEREBROVASCULAR DISEASE
}

\author{
PARVIN S ${ }^{1}$, HOQUE MM ${ }^{2}$, SULTANA N ${ }^{3}$, CHOWDHURY NS $^{4}, \mathrm{CHOWDHURY} \mathrm{SS}^{5}$, \\ AKHTER $\mathrm{S}^{6}$, NAOSHIN $Z^{7}$
}

\begin{abstract}
:
A case control study was carried out in the Department of Biochemistry, BSMMU from January to December 2007 to evaluate the association of uric acid with cerebrovascular disease (CVD) in a Bangladeshi population. A total number of 135 subjects of both sexes were grouped as group-É (CVD cases) and group-II (Healthy controls). Group-I include 85 cases, 59 were ischaemic cerebrovascular disease (ICVD) and 26 were haemorrhagic cerebrovascular disease (HCVD). By taking the history and doing the clinical examination and laboratory investigations diabetes mellitus, malignant disease, renal disease, thyroid disorder, liver disease \& diuretic medication were excluded from study subjects. Serum uric acid was measured in all study subjects. The mean serum uric acid concentration of CVD, ICVD, HCVD cases and control subjects were $5.98 \pm 1.52 \mathrm{mg} / \mathrm{dl}, 6.04 \pm 1.45 \mathrm{mg} / \mathrm{dl}, 5.85 \pm 1.68 \mathrm{mg} / \mathrm{dl} \& 5.00 \pm 1.35 \mathrm{mg} / \mathrm{dl}$ respectively. Serum uric acid found significantly increased in CVD, ICVD and HCVD cases in comparison to control subjects. No difference was found in serum uric acid in between ICVD and HCVD cases.
\end{abstract}

Key words: Uric acid, cerebrovascular disease, ischemic cerebrovascular disease, haemorrhagic cerebrovascular disease.

J Dhaka Med Coll. 2009; 18(1) : 15-19

\section{Introduction:}

Cerebrovascular disease (CVD) or stroke is one of the most common causes of mortality and longterm severe disability. It is the third leading cause of death after coronary heart disease (CHD) $\&$ malignancy and important cause of hospital admission in global perspective ${ }^{1 .}$ In Japan and other Asian countries including Bangladesh, CVD remains the most common disease ${ }^{2}$. There are two classical type of CVD from pathophysiological point of view: - Ischemic CVD (ICVD) \& Hemorrhagic CVD (HCVD). In ICVD that is caused by occlusion of cerebral vessels; thromboembolic phenomenon is primarily responsible, where hyperlipidemia and atherosclerosis plays a central role ${ }^{3}$. In HCVD that happens following the rupture of intracerebral or subarachnoid vessels; chronic hypertension plays a central role $\mathrm{e}^{4}$ As early as the $19^{\text {th }}$ century, it was known that serum uric acid levels are associated with hypertension. Large cohort studies have shown that serum uric acid is an important independent risk factor for cardiovascular mortality ${ }^{5}$, 6. Some studies reported an independent association between serum uric acid and $\mathrm{CHD}^{7}, 8$. An association was found between serum uric acid and stroke risk in diabetics and between serum uric acid \& fatal stroke in general population ${ }^{9}$, 10. For the last fifty years since the recognition of the association of hyperuricemia and increased cardiovascular risk due to atherosclerotic vascular diseases; researchers are trying hard to explore the molecular mechanism of this scenario. Hypertension remains the most common cause of stroke, and there is increasing evidence that an elevation in uric acid may cause primary hypertension. The Bogalusa Heart Study; found that uric acid levels in childhood predict the development of diastolic hypertension 10 years later. The Framingham study also found

1. Lecturer, Department of Biochemistry, Dhaka Medical College, Dhaka.

2. Professor, Department of Biochemistry, BSMMU, Dhaka.

3. Associate Professor, Department of Biochemistry, Dhaka Medical College, Dhaka

4. Assistant Professor, Department of Biochemistry, Dhaka Medical College, Dhaka

5. Assistant Professor, Department of Biochemistry, Dhaka Community Medical College, Dhaka.

6. Lecturer, Department of Biochemistry, Shaheed Suhrawardy Medical College, Dhaka.

7. Lecturer, Department of Biochemistry, Tejgaon College, Dhaka.

Correspondence: Dr. Shamima Parvin. 
uric acid to predict the development of hypertension ${ }^{11,12,13}$. Recent studies have found that elevated childhood serum uric acid levels are associated with increased blood pressure beginning in childhood and higher blood pressure levels that persist into adulthood, suggesting that early elevations in serum uric acid levels may play a key role in the development of human hypertension ${ }^{14}$. Both animal and human studies have recently shown that high uric acid levels may impair kidney function by causing glomerular damage and preglomerular arteriosclerosis, the two effects that ultimately result in arterial hypertension ${ }^{15}$. Uric acid contributes to endothelial dysfunction by impaired release of endothelial nitric oxide (NO) which is a potent vasodilator. It causes activation of renin-angiotensin system which produces hypertension. Soluble uric acid is also proinflammatory and stimulates synthesis of monocyte chemoattractant protein- 1 by vascular smooth muscle cells which is known to have a key role in stimulating macrophage infiltration in atherosclerotic vessels ${ }^{16}, 17$. We can't exclude the possibility of hyperuricemia to play a role in the pathogenesis of atherosclerosis: overwhelming evidences suggests that hyperuricemia is linked to obesity, HTN, hyperlipidemia, hyper-insulinemia and reduced insulin resistance ${ }^{18}$. Recent experimental and human studies have shown that hyperuricemia is associated with hypertension, systemic inflammation, and cardiovascular disease mediated by endothelial dysfunction and pathologic vascular remodeling ${ }^{19}$. On the other side of the coin, both in vitro and in vivo studies have shown the uric acid to be a powerful free radical scavenger in human and strongly supports its antioxidant activity by which paradoxically hyperuricemia expected to offer a number of benefits within the cardiovascular system and to be associated with good clinical prognosis in patients with stroke because cerebral infarction initiates a cascade of metabolic events in the surrounding tissues $\&$ free radicals mediated oxidative damage plays key role in pathogenesis of cerebral ischemia ${ }^{20}$, 21, 22. In Bangladesh, CVD stands for quite a sizeable number of mortality and morbidity causing a major socioeconomic challenge in the rehabilitation of stroke survivours. The best option for stroke still remains its prevention. So, we should take appropriate valuable measure against its prevention. It is possible to reduce the probability of stroke by curbing down hyperuricemia if they are related to stroke. So, the aim of this study is to evaluate the association between hyperuricemia with stroke in our population.

\section{Methods:}

This case-control study was carried out in the Department of Biochemistry, Bangabandhu Sheikh Mujib Medical University (BSMMU), Shahbag, Dhaka from January to December 2007. A total of 135 (one hundred and thirty five) subjects of both sexes were grouped as group-I (CVD cases), and group-II (Healthy control). Group-I included 85 cases, 59 were ICVD and 26 were HCVD. Among ICVD cases 42 were male and 17 were female with mean age of $58.34 \pm 7.01$ years and age range of 40-68 years and among HCVD cases 19 were male and 7 were female with mean age of $59.31 \pm 6.73$ years and age range of $45-68$ years. Group-II included 50 healthy controls, 37 were male and 13 were female with mean age of $50.48 \pm 5.50$ years and age range of 40-62 years. By taking the history and doing clinical examination and laboratory investigation diabetes mellitus, malignant disease, renal disease, thyroid disorder, liver disease $\&$ diuretic medication were excluded from study subjects. Informed written consent was taken from the patient or from his/her attendant. $5 \mathrm{ml}$ fasting venous blood was collected from all study subjects with full aseptic precaution Blood was allowed to clot and then centrifuged. Separated serum was then collected and preserved at $-35^{\circ} \mathrm{C}$ and later on used for the measurement of uric acid, lipid profile, creatinine and sugar concentration. All data were recorded systematically in a preformed data collection form and were expressed as mean \pm SD. Statistical analyses were performed by using SPSS for windows version 12.0. Mean values of the findings were compared between groups. One way ANOVA test \& multiple comparison (Bonferroni' $t$ ') test were used to see the level of significance. 95\% confidence limit $(p<0.05)$ was taken as level of significance.

\section{Results:}

The mean \pm SD of serum uric acid concentration of ICVD, HCVD cases and control subjects were $6.035 \pm 1.45 \mathrm{mg} / \mathrm{dl}$ with the range $2.80-8.60 \mathrm{mg} /$ $\mathrm{dl}, 5.85 \pm 1.68 \mathrm{mg} / \mathrm{dl}$ with the range $3.10-8.70$ $\mathrm{mg} / \mathrm{dl}$ and $5.00 \pm 1.35$ with the range $1.80-8.00$ $\mathrm{mg} / \mathrm{dl}$, respectively. 
Table-I

Grouping of study subjects with age and sex distribution

\begin{tabular}{|c|c|c|c|c|c|c|}
\hline \multirow[t]{2}{*}{ Study subjects } & & \multirow[t]{2}{*}{ Number } & \multicolumn{2}{|c|}{ Age in years } & \multicolumn{2}{|c|}{ Sex } \\
\hline & & & Mean \pm SD & Range & Male & Female \\
\hline \multirow[t]{2}{*}{ Group-I (CVD Cases) } & ICVD & 59 & $58.34 \pm 7.01$ & $40-68$ & 42 & 17 \\
\hline & HCVD & 26 & $59.31 \pm 6.73$ & $45-68$ & 19 & 7 \\
\hline Group-II (Healthy control) & 50 & $50.48 \pm 5.50$ & $40-62$ & 37 & 13 & \\
\hline
\end{tabular}

ICVD $=$ Ischaemic cerebrovascular disease

$\mathrm{HCVD}=$ Haemorrhagic cerebrovascular disease

Table-II

Comparison of serum uric acid level among the three groups of study subjects (ICVD, HCVD and control).

\begin{tabular}{lccccc}
\hline $\begin{array}{l}\text { Parameter } \\
(\text { mean } \pm \text { SD })\end{array}$ & $\begin{array}{c}\text { ICVD } \\
(\mathrm{n}=59)\end{array}$ & $\begin{array}{c}\text { HCVD } \\
(\mathrm{n}=26)\end{array}$ & $\begin{array}{c}\text { Control } \\
(\mathrm{n}=50)\end{array}$ & F-Value & P-Value \\
\hline Uric acid & $6.035 \pm 1.45$ & $5.85 \pm 1.68$ & $5.00 \pm 1.35$ & 7.083 & 0.001 \\
$(\mathrm{mg} / \mathrm{dl})$ & $(2.80-8.60)$ & $(3.10-8.70)$ & $(1.80-8.00)$ & & \\
\hline
\end{tabular}

Table-III

Comparison of serum uric acid between different groups of study subjects.

\begin{tabular}{lcc}
\hline \multicolumn{2}{l}{ Grouping of study subjects } & p-value \\
\hline Control & ICVD & 0.001 \\
Control & HCVD & 0.050 \\
ICVD & HCVD & 1.000 \\
\hline
\end{tabular}

\section{Discussion:}

In this present case-control study, serum uric acid concentration was measured in 85 diagnosed CVD patients (59 ICVD + 26 HCVD) and 50 healthy control subjects to evaluate the association of uric acid with CVD. The mean serum uric acid level found to be significantly high $(\mathrm{P}=0.001)$ in $\mathrm{CVD}$ cases compared to controls. This finding conforms to other similar studies done abroad $23,24,10,15$.

Bos et al. ${ }^{19}$ found a significant positive association between serum uric acid levels and the risk of both heart disease and stroke. Elevated uric acid levels were also found to be an independent risk factor for overall cardiovascular mortality ${ }^{5}$, but the Framingham Heart Study did not find uric acid to be an independent risk factor for cardiovascular disease ${ }^{25}$. A study done by Strasak et al. ${ }^{26}$ demonstrates for the first time in a large prospective male cohort that serum uric acid is independently related to the mortality from stroke. Serum uric acid level in ICVD cases were compared and found significantly higher $(\mathrm{P}=0.001)$ in comparison to their controls. A study done by Gariballa et al. ${ }^{27}$ also showed similar result but the studies done by Cherubini et al. ${ }^{28}$ found lower uric acid level on admission in patients with ischaemic stroke which showed a gradual increase over time. Patients with the worst early outcome (death or functional decline) had higher plasma uric acid levels than those who remained functionally stable. In our study we found higher uric acid level in cases than control subjects which is consistent with the study done by Cherubini et al. ${ }^{28}$ and in the present study, samples were actually collected on the $2^{\text {nd }}$ or $3^{\text {rd }}$ admission day rather $1^{\text {st }}$ day. Weir et al. ${ }^{29}$ measured uric acid levels in 2498 stroke patients within 24 to 48 hours of admission and found poorer outcome in subjects with higher serum uric acid levels. They concluded that independent of other prognostic factors; high serum uric acid levels predict poor outcome and higher vascular event rates in patients with stroke. In agreement with these findings, the authors advised interventions 
aimed at lowering uric acid to decrease the risk of stroke. In an accompanying editorial ${ }^{11}$, it is concluded that elevated uric acid is injurious rather than protective in subjects with stroke.

The mean serum uric acid of HCVD cases were compared with that of control and also found to be significantly higher $(p=0.050)$. This finding is consistent with the observation of Bos et al. ${ }^{19}$. There are several lines of evidences suggesting that hyperuricemia is associated with hypertension, through its direct role on vascular smooth muscle cell proliferation, endothelial dysfunction, decreased nitric oxide production, renal arteriosclerosis, proinflammatory features and local activation of the renin-angiotensin system ${ }^{30,10 . ~ S i n c e ~}$ hypertension remains the most common risk factor for hemorrhagic stroke, inducing hypertension hyperuricemia may contributes to HCVD. The serum uric acid were compared between ICVD and HCVD, but no significant difference $(p=1.00)$ found. Study done by Stemmermann et al. ${ }^{31}$ identified similar uric acid status for ICVD and HCVD. A study done by Chamorro et al. ${ }^{22}$ in patients with ischemic stroke showed $12 \%$ increase in the odds of good clinical outcome for each miligram per deciliter increase of uric acid. The finding reinforces the relevance of oxidative damage in ischemic stroke and the protective role of uric acid as antioxidant in these conditions. Uric acid is regarded as an effective natural antioxidant like ascorbate and prevents the oxidative inactivation of endothelial enzymes and preserves the ability of the endothelium to mediate vascular dilatation in the face of oxidative stress ${ }^{32}$. On the other hand with regard to the underlying pathophysiological mechanism, human atherosclerotic plaque has been shown to contain a considerable amount of uric acid, and hyperuricemia is incriminated to promote thrombus formation, increased production of oxygen free radicals, acceleration of LDL oxygenation and lipid per oxidation. Each of these factors is known to play a crucial role in the progression of atherosclerosis which may ultimately contribute to ICVD. Some researchers proposed an "antioxidant - prooxidant urate redox shuttle" mechanism for uric acid. Serum uric acid in early stages of atherosclerotic process is known to act as an antioxidant but later on when serum uric acid concentration increases paradoxically antioxidant uric acid become prooxidant ${ }^{12}$. Thus it appears that uric acid is not an inert molecule as has historically been believed but can instead play a role in many biological functions. Uric acid can be both beneficial as an antioxidant and free radical scavenger and deleterious by promoting atherosclerotic process as prooxidant at an elevated level. Hyperuricemia found in our CVD cases permissively supports this idea.

\section{Conclusion:}

It can be concluded from this study that Hyperuricemia is associated with CVD. Hyperuricemia may have additive or synergistic effect on pathophysiology of CVD. Hyperuricemia appear to affect ICVD and HCVD equally. Prospective study with large sample is recommended to evaluate the serum uric acid as risk factors of CVD.

\section{References:}

1. Bonita R. Epidemiology of stroke. Lancet. 1992; 339: 342-4.

2. Shinohara Y. Life style is not the only cause of stroke - risk factors recently attracting attention. JAMA. 2001; 44: 177-81.

3. Allen CMC, Lueck CJ. Disease of nervous system. In: R Haslet, ER Chilver, JAA Hunter and NA Boon. eds. Davidson's principles and practice of medicine. $18^{\text {th }}$ ed. London: Churchill Livingstone; 1999. p. 923-1023.

4. Smith WS, Hauser SL, Easton JD. Cerebrovascular diseases. In: Braunwald E, Fauci AS, Kasper DL, Hauser SL, Longo DL, JL Jameson. eds. Harrison's Principles of Medicine. $15^{\text {th }}$ ed, USA: McGrawHill; p. 2369.

5. Fang J, Alderman MH. Serum Uric Acid and Cardiovascular Mortality: The NHANESI Epidemiologic Follow-up Study, 1971-1992. JAMA. 2000; 283: 2404-10.

6. Niskanen LK, Laaksonen DE, Nyyssönen K, Alfthan G, Lakka HM, Lakka TA, et al. Uric acid level as a risk factor for cardiovascular and all-cause mortality in middle-aged men - a prospective cohort study. Arch Intern Med. 2004; 164: 1546-51.

7. Goldberg RJ, Burchfiel CM, Benfante R, Chiu D, Reed DM ands Yano K. Lifestyle and biologic factors associated with atherosclerotic disease in 
middle-aged men: 20 years findings from the Honolulu Heart Program. Arch Intern Med. 1995; 155: 686-94.

8. Liese AD, Hense HW, Lowel H, Doring A, Tietze M, Keil U. Association of serum uric acid with all-cause and cardiovascular disease mortality and incident myocardial infarction in the MONICA Augsburg Cohort. Epidemiology. 1999; 10: 39197.

9. Lehto S, Niskanen L, Ronnemaa T, Laakso M. Serum uric acid is a strong predictor of stroke in patients with non-insulin-dependent diabetes mellitus. Stroke. 1998; 29:635-39.

10. Mazza A, Pessina AC Pavei A, Scarpa R, Tikhonoff V, Casiglia E. Predictors of stroke mortality in elderly people from the general population: the cardiovascular study in the elderly. Eur J Epidemiol. 2001; 17: 1097-1104.

11. Kanellis J, Johnson RJ. Elevated uric acid and ischemic stroke: accumulating evidence that it is injurious and not neuroprotective. [Editorial comment]. Stroke. 2003; 34(8):1956-7.

12. Hayden MR, Tyagi SC. Uric acid: a new look at an old risk marker for cardiovascular disease, metabolic syndrome, and type 2 diabetes mellitus: the urate redox shuttle. Nutr Metabol. 2004; 1: 10 .

13. Johnson RJ, Feig DI, Herrera-Acosta J, Kang DukHee. Resurrection of uric acid as a causal risk factor in essential hypertension. Hypertension. 2005; 45: 18-20.

14. Alper AB, Chen Jr.W, Yau L, Srinivasan SR, Berenson GS, Hamm LL. Childhood uric acid predicts adult blood pressure: the Bogalusa Heart Study. Hypertension. 2005; 45: 34-8.

15. Bos MJ, Koudstaal PJ, Hofman A, Witteman JCM, Breteler MMB. Uric acid is a risk factor for myocardial infarction and stroke. Stroke. 2006; 37: 1503-7.

16. Weir CJ, Muir SW, Walters MR, Lees KR. Serum urate as an independent predictor of poor outcome and future vascular events after acute stroke. Stroke. 2003; 34: 1951-7.

17. Johnson RJ, Kang Duk-Hee, Feig D, Kivlighn S, Kanellis $\mathrm{J}$, Watanabe $\mathrm{S}$, et al. Is there a pathogenetic role for uric acid in hypertension and cardiovascular and renal disease? Hypertension. 2003; 41: 1183-90.

18. Facchini F, Chen YDI, Hollenbeck CB, Reaven GM. Relationship between resistance to insulinmediated glucose uptake, urinary uric acid clearance, and plasma uric acid concentration. JAMA. 1991; 266: 3008-11.
19. Kang Duk-Hee, Park Sung-Kwang, Lee In-Kyu, Johnson RJ. Uric acid induced C-reactive protein expression: implication on cell proliferation and nitric oxide production of human vascular cells. J Am Soc Nephrol. 2005; 16: 3553-62.

20. Love S. Oxidative stress in brain ischaemia. Brain Pathol. 1999; 9: 119-31.

21. Nieto FJ, Iribarren C, Gross MD, Comstock GW, Cutler RG. Uric acid and serum antioxidant capacity: a reaction to atherosclerosis? Atherosclerosis. 2000; 148: 131-9.

22. Chamorro A, Obach V, Cervera A, Revilla M, Deulofeu R, Aponte JH. Prognostic significance of uric acid serum concentration in patients with acute ischemic stroke. Stroke. 2002; 33: 1048-52.

23. Milionis HJ, Kalantzi KJ, Goudevenos JA, Seferiadis K, Mikhailidis DP, Elisaf MS. Serum uric acid levels and risk for acute ischaemic nonembolic stroke in elderly subjects. J Intern Med. 2005; 258: 435-41.

24. Longo-Mbenza B, Luila EL, Mbete P, Vita EK. Is hyperuricemia a risk factor of stroke and coronary heart disease among Africans? Int J Cardiology. 1999; 71: 17-22.

25. Culleton BF, Larson MG, Kannel WB, Levy D. Serum uric acid and risk for cardiovascular disease and death. Ann Intern Med. 1999; 131: 7-13.

26. Strasak A, Ruttmann E, Brant L, Kelleher C, Klenk $\mathrm{J}$, Concin $\mathrm{H}$, et al. Serum uric acid and risk of cardiovascular mortality: a prospective long-term study of 83683 Austrian men. Clin Chem. 2008; 54(2): 273-84.

27. Gariballa SE, Hutchin TP, Sinclair AJ. Antioxidant capacity after acute ischaemic stroke. Q J Med. 2002; 95: 685-90.

28. Cherubini A, Polidori MC, Bregnocchi M, Pezzuto $\mathrm{S}$, Cecchetti R, Ingegni T. Antioxidant profile and early outcome in stroke patients. Stroke. 2000; 31: 2295-2300.

29. Weir CJ, Muir SW, Walters MR, Lees KR. Serum urate as an independent predictor of poor outcome and future vascular events after acute stroke. Stroke. 2003; 34: 1951-1957.

30. Syamala S, Li J, Shankar A. Association between serum uric acid and prehypertension among US adults. J Hypertension. 2007; 25(8): 1583-1589.

31. Stemmermann GN, Hayashi T, Resch JA, Chung CS, Reed DM, Rhoads GG. Risk factors related to ischemic and hemorrhagic cerebrovascular disease at autopsy: the Honolulu Heart Study. Stroke. 1984; 15: 23-8.

32. Becker BF. Towards the physiological function of uric acid. Free Radic Biol Med. 1993; 14: 615-31. 